\title{
A single nucleotide polymorphism in ADIPOQ predicts biochemical recurrence after radical prostatectomy in localized prostate cancer
}

\author{
Chengyuan Gu${ }^{1,2, *}$, Yuanyuan Qu ${ }^{1,2, *}$, Guiming Zhang ${ }^{1,2,3}$, LiJiang Sun ${ }^{3}$, Yao Zhu ${ }^{1,2}$ \\ and Dingwei $\mathbf{Y e}^{1,2}$ \\ ${ }^{1}$ Department of Urology, Fudan University Shanghai Cancer Center, Shanghai, China \\ 2 Department of Oncology, Shanghai Medical College, Fudan University, Shanghai, China \\ ${ }^{3}$ Department of Urology, The Affiliated Hospital of Qingdao University, Qingdao, China \\ * These authors have contributed equally to this work \\ Correspondence to: Yao Zhu, email: mailzhuyao@163.com
}

Dingwei Ye, email: dwyeli@163.com

Keywords: biochemical recurrence, adiponectin, prostate cancer, radical prostatectomy, single-nucleotide polymorphism Received: May 05, $2015 \quad$ Accepted: July 16, $2015 \quad$ Published: July 22, 2015

This is an open-access article distributed under the terms of the Creative Commons Attribution License, which permits unrestricted use, distribution, and reproduction in any medium, provided the original author and source are credited.

\section{ABSTRACT}

Adiponectin has been implicated in prostate cancer (PCa) aggressiveness. However, the role of genetic variations in the adiponectin (ADIPOQ) gene in PCa progression remains unknown. To determine whether genetic variants in ADIPOQ are associated with the risk of biochemical recurrence (BCR) after radical prostatectomy (RP). We evaluated three common ADIPOQ polymorphisms in 728 men with clinically localized PCa who underwent RP. Multivariable Cox proportional hazards models and Kaplan-Meier analysis were used to assess their prognostic significance on BCR. The plasma adiponectin concentrations were measured by enzyme-linked immunosorbent assay. ADIPOQ rs182052 variant allele was associated with both increased risk of BCR [HR: 2.44; 95\% confidence interval (CI): 1.57-3.79, $P=6 \times 10^{-5}$ ] and decreased adiponectin level $(\beta=-0.048, P=0.004)$. Stratified analyses demonstrated that the association was more pronounced in men with higher visceral adipose tissue. Our data support that the ADIPOQ rs182052 SNP may be a predictive biomarker for BCR after RP by a possible mechanism of altering the adiponectin level. If validated, genetic predictors of outcome may help individualizing treatment for PCa.

\section{INTRODUCTION}

There is extensive evidence implicating obesity in prostate cancer $(\mathrm{PCa})$ progression. It is increasingly clear that obesity is associated with a greater risk of higher grade and late-stage disease at the time of diagnosis [1]. Also, evidence of the association between abdominal obesity and biochemical recurrence (BCR) following radical prostatectomy (RP) has expanded significantly in recent years [2].

Considering that adipose tissue is a metabolically active endocrine organ, one of the major links between obesity and aggressive $\mathrm{PCa}$ is aberrant secretion and signaling of adipokines [3]. The properties of visceral adipose tissue (VAT), subcutaneous adipose tissue (SAT) and periprostatic adipose tissue (PPAT) can be distinguished depending on the distribution of adipose tissue $[4,5]$. Adiponectin is the most abundant adipokine with lower levels seen in individuals with unfavorable metabolic conditions such as visceral obesity [6]. Specifically, adiponectin levels were found to be reduced significantly in metastatic PCa patients versus those with organ-confined disease [7], suggesting its involvement in $\mathrm{PCa}$ progression. It has been shown to inhibit $\mathrm{PCa}$ cell proliferation and invasion via restraining epithelial-tomesenchymal transition process [8].

To our knowledge, three $A D I P O Q$ single nucleotide polymorphisms (SNPs) (rs182052, rs266729 and 
Table 1: Clinicopathologic characteristics of the study populations

\begin{tabular}{|c|c|c|c|c|c|c|}
\hline \multirow[b]{2}{*}{ Variables } & \multicolumn{3}{|c|}{ Qingdao, $N=312$} & \multicolumn{3}{|c|}{ Shanghai, $N=426$} \\
\hline & BCR & Non-BCR & $P$ & BCR & Non-BCR & $P$ \\
\hline Age, years & $67(52-79)$ & $68(46-80)$ & 0.991 & $68(58-79)$ & $68(46-82)$ & 0.951 \\
\hline \multicolumn{7}{|l|}{ BMI, $\mathrm{kg} / \mathrm{m}^{2}$} \\
\hline$<24$ & $60(77.9)$ & $181(77.0)$ & 0.870 & $46(46.0)$ & $176(54.0)$ & 0.162 \\
\hline$\geq 24$ & $17(22.1)$ & $54(23.0)$ & & $54(54.0)$ & $150(46.0)$ & \\
\hline \multicolumn{7}{|l|}{$\mathrm{PSA}, \mathrm{ng} / \mathrm{ml}$} \\
\hline$\leq 20$ & $40(51.9)$ & $161(68.5)$ & 0.008 & $39(39.0)$ & $210(64.4)$ & $<0.001$ \\
\hline$>20$ & $37(48.1)$ & $74(31.5)$ & & $61(61.0)$ & $116(35.6)$ & \\
\hline \multicolumn{7}{|l|}{ Gleason score } \\
\hline$\leq 7(3+4)$ & $20(26.0)$ & $107(45.5)$ & 0.002 & $27(27.0)$ & $173(53.1)$ & $<0.001$ \\
\hline$\geq 7(4+3)$ & $57(74.0)$ & $128(54.5)$ & & $73(73.0)$ & $153(46.9)$ & \\
\hline \multicolumn{7}{|l|}{ Pathologic stage } \\
\hline $\mathrm{T} 1-2$ & $24(31.2)$ & $138(58.7)$ & $<0.001$ & $49(49.0)$ & $233(71.5)$ & $<0.001$ \\
\hline$\geq \mathrm{T} 3$ & $53(68.8)$ & $97(41.3)$ & & $51(51.0)$ & $93(28.5)$ & \\
\hline \multicolumn{7}{|l|}{ Lymph node involvement } \\
\hline Negative & $59(76.6)$ & $216(91.9)$ & $<0.001$ & $75(75.0)$ & $304(93.3)$ & $<0.001$ \\
\hline Positive & $18(23.4)$ & $19(8.1)$ & & $25(25.0)$ & $22(6.7)$ & \\
\hline Follow-up, months & 36.3 & & & 37.7 & & \\
\hline Adiponectin levels, $\mu \mathrm{g} / \mathrm{ml}$ & & & & $7.0(4.2-14.3)$ & $7.1(4.1-14.6)$ & 0.225 \\
\hline
\end{tabular}

rs3774262) were shown to be associated with both PCa susceptibility and adiponectin levels [9, 10]. They have been found to either have potentially functionality [11] or are associated with $\mathrm{PCa}$ clinicopathologic characteristics [10]. It is conceivable that these SNPs might influence PCa clinical outcome through modulation of adiponectin levels, which promotes a favorable microenvironment for PCa progression. In this regard, we sought to explore their prognostic significance on BCR among men with localized PCa who underwent RP.

\section{RESULTS}

Patient characteristics are shown in Table 1. The median follow up times were 36.3 and 37.7 months, and there were $79(25.3 \%)$ and $100(23.5 \%)$ patients experienced BCR in Study 1 and Study 2, respectively. PSA levels, pathologic stage, lymph node involvement and Gleason score were significantly associated with BCR in both cohorts $(P<0.016)$.
In Study 1, we found a significant association of rs182052, but not rs266729 or rs3774262, with an increased risk of BCR (HR: 2.16, 95\% CI: $1.07-$ 4.38; Table 2). This association of rs182052 remained significant in Study 2 after adjusting for currently known clinical factors (HR: 2.39, 95\% CI: 1.35-4.22). There was an elevation in risk of BCR with the number of variant $\mathrm{A}$ allele in both cohorts and combined analysis (log-rank $P$ $=0.005$, Figure 1A, $1 \mathrm{~B}$ and $1 \mathrm{C}$ ).

To investigate the effect of SNPs on circulating adiponectin levels, we next evaluated differences in adiponectin levels by SNPs in Study 2. Consistent with previous report, plasma adiponectin levels were affected by rs182052. Individuals with rs182052 variant A allele had lower levels of plasma adiponectin $(\beta=-0.048, P$ $=0.004)$. We did not observe significant differences in adiponectin levels by rs266279 and rs3774262 $(\beta=0.003$, $P=0.867$ and $\beta=-0.033, P=0.081$, respectively).

In stratification analyses, we further assessed whether SNPs associations with BCR risk varied according to anthropometric measurements by the CT
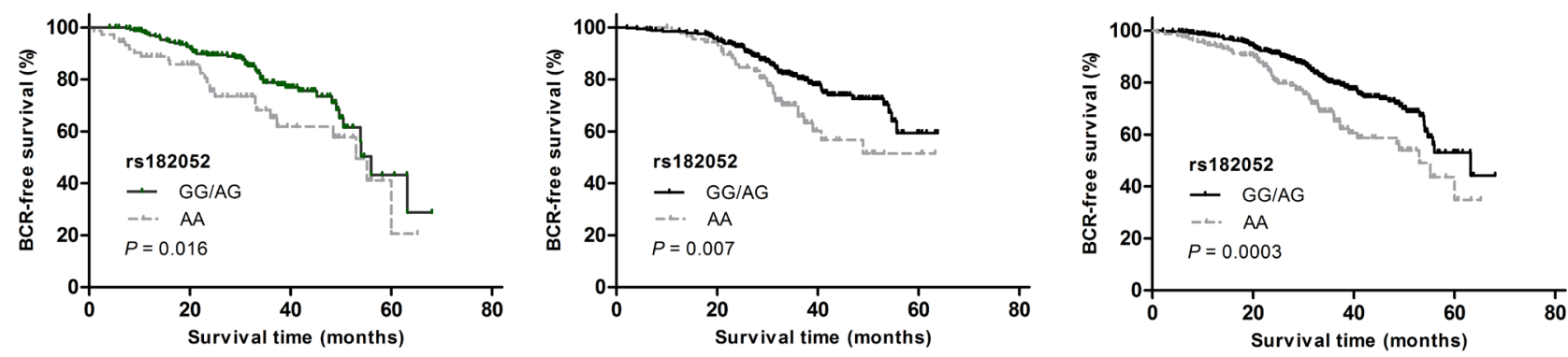

Figure 1: Kaplan-Meier survival curves for BCR-free survival according to $A D I P O Q$ rs182052 by recessive model in (a) Study 1, (b) Study 2 and (c) combined analysis. 
Table 2: Associations between $A D I P O Q$ SNPs and BCR

\begin{tabular}{|c|c|c|c|c|c|c|c|c|c|c|c|c|}
\hline \multirow[b]{2}{*}{ SNP } & \multicolumn{4}{|c|}{ Qingdao, $N=312$} & \multicolumn{4}{|c|}{ Shanghai, $N=426$} & \multicolumn{4}{|c|}{ Combined, $\mathrm{N}=738$} \\
\hline & BCR, n $(\%)$ & Non-BCR, n (\%) & $\operatorname{HR}(95 \% \text { CI })^{\mathrm{a}}$ & $P$ & BCR, n (\%) & Non-BCR, n (\%) & HR $(95 \% \text { CI })^{a}$ & $\boldsymbol{P}$ & BCR, n (\%) & Non-BCR, n (\%) & HR $(95 \% \text { CI })^{\mathrm{a}}$ & $P$ \\
\hline \multicolumn{13}{|l|}{ rs 182052} \\
\hline GG & $12(15.6)$ & $70(29.8)$ & 1.00 & & $21(21.0)$ & $107(32.8)$ & 1.00 & & $33(18.6)$ & $177(31.6)$ & 1.00 & \\
\hline $\mathrm{AG}$ & $40(51.9)$ & $116(49.4)$ & $1.25(0.64-2.41)$ & 0.517 & $50(50.0)$ & $157(48.2)$ & $1.59(0.95-2.65)$ & 0.077 & $90(50.8)$ & $273(48.7)$ & $1.53(1.02-2.28)$ & 0.04 \\
\hline $\mathrm{AA}$ & $25(32.5)$ & $49(20.8)$ & $2.16(1.07-4.38)$ & 0.032 & $29(29.0)$ & $62(19.0)$ & $2.39(1.35-4.22)$ & 0.003 & $54(30.6)$ & $111(19.7)$ & $2.44(1.57-3.79)$ & $6 \times 10^{-5}$ \\
\hline AG/AA vs. GG & & & $1.49(0.79-2.80)$ & 0.218 & & & $1.81(1.12-2.93)$ & 0.016 & & & $1.75(1.20-2.57)$ & 0.004 \\
\hline$\underset{\text { rs } 266729}{\mathrm{GG} / \mathrm{AG} \text { vs. AA }}$ & & & $1.74(1.08-2.80)$ & 0.014 & & & $1.78(1.14-2.77)$ & 0.011 & & & $1.77(1.28-2.45)$ & $5 \times 10^{-4}$ \\
\hline $\mathrm{CC}$ & $39(50.6)$ & $120(51.1)$ & 1.00 & & $52(52.0)$ & $167(51.2)$ & 1.00 & & $91(51.4)$ & $287(51.2)$ & 1.00 & \\
\hline CG & $33(42.9)$ & $96(40.9)$ & $1.24(0.78-1.98)$ & 0.369 & $41(41.0)$ & $134(41.1)$ & $1.13(0.75-1.71)$ & 0.564 & $74(41.8)$ & $230(41.0)$ & $1.22(0.90-1.66)$ & 0.206 \\
\hline GG & $5(6.5)$ & $19(8.0)$ & $1.48(0.57-3.86)$ & 0.423 & $7(7.0)$ & $25(7.7)$ & $1.09(0.49-2.41)$ & 0.831 & $12(6.8)$ & $44(7.8)$ & $1.16(0.63-2.13)$ & 0.635 \\
\hline $\mathrm{CG} / \mathrm{GG}$ vs. $\mathrm{CC}$ & & & $1.26(0.80-1.99)$ & 0.311 & & & $1.12(0.76-1.67)$ & 0.564 & & & $1.21(0.90-1.63)$ & 0.206 \\
\hline $\mathrm{CC} / \mathrm{CG}$ vs. $\mathrm{GG}$ & & & $1.17(0.47-2.92)$ & 0.743 & & & $1.04(0.48-2.24)$ & 0.929 & & & $1.03(0.57-1.86)$ & 0.920 \\
\hline \multicolumn{13}{|l|}{ rs3774262 } \\
\hline GG & $35(45.5)$ & $104(44.3)$ & 1.00 & & $41(41.0)$ & $143(43.9)$ & 1.00 & & $76(42.9)$ & $247(44.0)$ & 1.00 & \\
\hline$A G$ & $37(48.1)$ & $114(48.5)$ & $1.13(0.71-1.81)$ & 0.609 & $50(50.0)$ & $156(47.9)$ & $1.44(0.95-2.19)$ & 0.085 & $87(49.2)$ & $270(48.1)$ & $1.34(0.99-1.83)$ & 0.062 \\
\hline $\mathrm{AA}$ & $5(6.4)$ & $17(7.2)$ & $1.34(0.51-3.55)$ & 0.553 & $9(9.0)$ & $27(8.2)$ & $1.33(0.64-2.77)$ & 0.449 & $14(7.9)$ & $44(7.9)$ & $1.14(0.64-2.02)$ & 0.663 \\
\hline $\mathrm{AG} / \mathrm{AA}$ vs. GG & & & $1.15(0.73-1.82)$ & 0.546 & & & $1.49(0.99-2.23)$ & 0.051 & & & $1.31(0.97-1.77)$ & 0.077 \\
\hline GG/AG vs. AA & & & $1.04(0.42-2.60)$ & 0.927 & & & $1.08(0.54-2.17)$ & 0.829 & & & $1.08(0.54-2.17)$ & 0.943 \\
\hline
\end{tabular}

Table 3: Stratification analysis for associations between $A D I P O Q$ SNPs and BCR by anthropometric measurements

\begin{tabular}{|c|c|c|c|c|c|}
\hline \multirow[t]{2}{*}{ Variables } & \multicolumn{2}{|c|}{$\begin{array}{l}\text { rs182052 } \\
\text { (BCR/Non-BCR) }\end{array}$} & \multirow[t]{2}{*}{$\operatorname{HR}(95 \% \mathrm{CI})^{\mathrm{a}}$} & \multirow[t]{2}{*}{$P^{\mathrm{a}}$} & \multirow[t]{2}{*}{$P^{\mathrm{b}}$} \\
\hline & AA & $\mathrm{AG} / \mathrm{GG}$ & & & \\
\hline \multicolumn{6}{|l|}{ VAT } \\
\hline$<$ Median & $3 / 23$ & $14 / 64$ & $1.15(0.29-1.36)$ & 0.837 & 0.028 \\
\hline$>$ Median & $15 / 11$ & $21 / 57$ & $2.53(1.75-5.14)$ & 0.010 & \\
\hline \multicolumn{6}{|l|}{ PPF } \\
\hline$<$ Median & $10 / 12$ & $23 / 59$ & $1.79(0.80-4.04)$ & 0.158 & 0.913 \\
\hline$>$ Median & $7 / 18$ & $13 / 66$ & $1.58(0.58-4.34)$ & 0.372 & \\
\hline \multicolumn{6}{|l|}{ SAT } \\
\hline$<$ Median & $9 / 13$ & $21 / 60$ & $1.24(0.54-2.87)$ & 0.608 & 0.053 \\
\hline$>$ Median & $8 / 17$ & $15 / 65$ & $2.04(0.86-4.82)$ & 0.106 & \\
\hline \multicolumn{6}{|l|}{ BMI } \\
\hline$<24$ & $10 / 31$ & $36 / 145$ & $1.01(0.87-1.35)$ & 0.281 & 0.622 \\
\hline$\geq 24$ & $11 / 31$ & $43 / 119$ & $1.09(0.54-2.18)$ & 0.808 & \\
\hline
\end{tabular}

${ }^{a}$ Adjusted for age, BMI and smoking status.

${ }^{\mathrm{b}} P$ value for homogeneity test.

scan which were available for 208 patients (Table 3 ). The association between rs 182052 and risk of BCR was more pronounced in men with higher VAT (HR: 2.53 , 95\% CI: $1.75-5.14 ; P=0.01)$. The BCR and Non-BCR cases were similar with respect to the anthropometric measurements (Supplementary Table 1). There were no SNPs associated with these anthropometric measurements (Supplementary Table 2).

\section{DISCUSSION}

Our study among men with clinically localized PCa evaluated whether three established susceptibility loci in $A D I P O Q$ influenced outcomes after RP. Presence of the minor allele in SNP rs182052 conferred a significant increased risk of BCR while controlling for known clinicopathologic risk factors, suggesting that this variant contribute independent data beyond currently used predictors. We found no associations between polymorphisms in the other two SNPs and BCR.

SNP rs182052 is located in the first intron of the ADIPOQ gene which contains a gene expression enhancer element [12]. In silco analysis showed rs182052 G>A changing confers a loss of a Sp1-binding site and gain of a CCAAT/enhancer-binding protein $(\mathrm{C} / \mathrm{EBP}) \beta$-binding site, 
which are both involved in adipocyte differentiation [13, 14]. This locus was identified by Dhillon et al. in a nested case-control study, whereby the A allele of rs182052 was associated with PCa predisposition [9]. The high-risk allele for Pca development aligned with worse prognosis, the plausible mechanisms of these associations may relate to circulating adiponectin levels.

In that respect, adiponectin is known to act as a potent inhibitor for PCa cells proliferation and invasion [15-17]. Adiponectin was shown to activate AMPactivated protein kinase (AMPK) in PCa cells, which in turn is involved in the anti-growth action via reduction in tumour protein translation [18]. Aside from AMPK, adiponectin is a potent inhibitor of PI3K/AKT /mTOR that is able to reduce cancer cell growth exerted by insulin and growth factor-induced signaling [19]. Circulating hormones and growth factors can also directly regulate tumor cell growth, or influence tumorigenesis through modifications of the stromal microenvironment composed of fibroblasts, immune-vascular and other cells [20]. For these reasons, a (genetically determined) modulation of adipoenctin in the tumor microenvironment could have a decisive role in determining prognosis for PCa.

Genetic studies have previously implicated the $A D I P O Q$ locus for a role in influencing variation in adiponectin levels [21]. Very strong evidence for linkage of serum adiponectin levels to rs 182052 has previously been found in two independent samples of Caucasian females from the Chingford Study and Twins UK cohort [22] and evidence for linkage has also been reported from at least four other European white populations [9, 2325]. In Asian populations association tests also revealed significant association between the presence of the minor A allele and decrease in serum adiponectin [26, 27]. Consistent with these published data, we demonstrated that patients with rs182052 AA genetic background may maintain lower adiponectin levels than AG or GG carriers. Considering that rs182052 variant AA genotype was inversely associated with risk of BCR, these genotypephenotype and genotype-risk associations were in the expected inverse directions to each other, suggesting a biological causal relationship.

Adipose tissue has an important role in more aggressive $\mathrm{PCa}$ since it display pivotal endocrine functions through the secretion of specific adipokines [3]. In the stratified analyses determined by body composition, we found indications of effect modification of rs182052 by high VAT. VAT and SAT are key contributors to abdominal obesity but differ in their structural composition, metabolic activity, and functional significance [4]. Individuals with increased VAT are at greater risk of developing metabolic disease, than are those with similar amounts of SAT [28]. The accumulation of VAT but not SAT mass is an independent predictor of reduced serum adiponectin levels [29]. The molecular mechanisms underlying the relationship may be that visceral adipocytes not only have lower levels of adiponectin expression but also reduced ability to functionally secrete this specific adipokine than subcutaneous adipocytes [30]. Thus, the adverse biologic functions of VAT may create a microenvironment favoring the development of more aggressive PCa. Thus, accounting for these risk factors and their potential interactions with genetic factors could result in larger discrimination in risk stratification. The absence of interaction with PPF suggests that other factors likely contribute to $\mathrm{PCa}$ recurrence, due in part to the high levels of IL-6 and VEGF in PPF [20].

In the current study, the rate of BCR was higher compared with previous American men studies [31]. On the other hand, BCR rates range from $10 \%$ to $35 \%$ in men undergoing RP worldwide [32] and our results were similar with studies in Asian countries [33-35]. One possible explanation for the rates of BCR differences relates to differential PSA screening situation. In China, where PSA screening is not as common as in the United States and Europe, many patients are diagnosed at more advanced stages. In the current study, 39.8\% cases had stage 3-4 cancer. Advanced stages predict poorer prognosis after RP. In addition, cancer control rates following RP largely depend on the definition of BCR [32].

To the best of our knowledge, this is the first study to describe the association between genetic variations in the adiponectin gene with respect to clinical outcomes of PCa. Our data benefit from two independent patient populations from different regions of China with comprehensive adiposity phenotypes. In agreement with previous studies [36, 37], we found that PSA, Gleason score, lymph node involvement and disease stage were among the most important predictors of BCR. Thus, the results of this study are strengthened by these wellknown prognostic factors of PCa recurrence. However, there are some limitations to consider in interpreting our study findings. First, the current findings are hypothesis generating, and the selected SNPs in our study did not fully cover the $A D I P O Q$ gene. Although we chose to sequence three $A D I P O Q$ SNPs based on previous study findings, some possible significant SNPs might be missed. A more comprehensive analysis of the ADIPOQ gene would be a future goal. Second, the relatively small sample size of the study might limit the power to reveal additional modest associations. Finally, our homogeneous Chinese Han population might make our findings less generalizable to other ethnic groups. Thus, our results warrant a largerscale study with a longer follow-up period and in other ethnic populations for further validation.

We conclude that a polymorphism in the $A D I P O Q$ gene is statistically significantly associated with clinical outcome in localized PCa patients received RP and this association may be modified by visceral obesity. Our results support that $A D I P O Q$ genetic variations impact adiponectin exposure to potentially promote cancer growth and proliferation. Further functional studies are required to 
fully clarify the impact of variations in the $A D I P O Q$ gene and $\mathrm{PCa}$ recurrence at the molecular level. Understanding the risk in individual patients will contribute to clinical prediction of prognosis, treatment options and approaches for secondary prevention.

\section{MATERIALS AND METHODS}

\section{Study population}

This study recruited 738 men with localized $\mathrm{PCa}$ who underwent RP from two centers in China. The first cohort (Study 1) consisted of 312 patients from the Affiliated Hospital of Qingdao University and Fudan University Shanghai Cancer Center between 2002 and 2005. The replication cohort (Study 2) is composed of 426 men recruited at Fudan University Shanghai Cancer Center between 2006 and 2009. All patients were followed up by serial PSA test every 3 months. Disease stage was determined according to criteria established by the American Joint Committee on Cancer (AJCC) tumornode-metastasis (TNM) classification system [AJCC Staging Manual, sixth edition, 2002]. Histopathological grading of the RP specimens was performed according to the Gleason score system. The clinical information were abstracted from the archival medical records. RP patients who received adjuvant hormone therapy or radiotherapy were excluded. BCR was defined as 2 consecutive PSA measurements $>0.2 \mathrm{ng} / \mathrm{mL}$ at an interval of $>3$ months, and the date of this event was set to the first of these two test occasions [38]. This study was approved by the Institutional Review Board of Fudan University Shanghai Cancer Center and the Affiliated Hospital of Qingdao University, and a written informed consent was obtained from each participant,

\section{Laboratory measurements}

The ADIPOQ gene has two major haplotype blocks. We selected to genotype rs266729 (5' flanking region), rs 182052 (intron 1) to tag block 1 and rs3774262 (intron 2) to tag block 2. These PCa risk-associated SNPs were reported to be significantly associated with serum adiponectin simultaneously [9, 10]. Genotyping was done after extraction of DNA from whole blood using a standard QIAmp kit (QIAGEN Inc.) protocol using TaqMan real-time PCR method as described previously [10]. All SNPs had greater than 99\% completion and the concordance was $100 \%$ for duplicated specimens. In 426 cases from FUSCC, plasma adiponectin was measured by an enzyme-linked immunosorbent assay (Abcam, USA) as reported previously [10].

\section{Anthropometric measurements}

BMI $\geq 24 \mathrm{~kg} / \mathrm{m}^{2}$ was defined as overweight according to the Chinese Working Group on Obesity guideline [39]. Abdominal VAT, SAT and PPAT were measured in preoperative computed tomography (CT) images in a subset of 208 patients using the average of 2 sections as standardized techniques. The quantities of abdominal VAT and SAT were measured at the level of the umbilicus (approximately the level of L4-L5) with patients in the supine position [40]. The measurement of PPF was performed on a transverse section at the level of caput femoris and greater trochanter of the femur [41]. The adipose area within the delineated contours of the CT was automatically calculated by ImageJ software based on predefined Hounsfield unit thresholds (-190 to -30$)$.

\section{Statistical analysis}

Continuous variables without normal distribution were compared by the Mann-Whitney U -test. Categorical variables were compared by the $x^{2}$ test or Fisher's exact test. Adiponecin were ln-transformed to achieve a normal distribution. Hardy-Weinberg equilibrium (HWE) for evaluation of genotype frequencies was performed by the goodness-of fit $\chi 2$ test. All SNPs were in agreement with HWE $(P=0.63$ for rs $266729,0.73$ for rs 182052 and 0.22 for rs3774262). The association between SNPs and $\mathrm{PCa}$ recurrence was assessed with hazard ratios (HR) and 95\% CI estimated by Cox proportional hazards regression analysis under different genetic models. All analyses were adjusted for known prognostic factors including age, disease stage, Gleason score, lymph node involvement and PSA at diagnosis. The BCR-free survival interval was estimated using the Kaplan-Meier method, and the significance was determined using the log-rank test. Multiple linear regression analysis was used to examine the relationship between SNPs, adiponectin levels and anthropometric measurements. Anthropometric measurements were dichotomized based on their distribution in stratification analysis. All reported $P$-values are 2-sided. SAS version 9.1 (SAS institute Inc.) was used for all analyses.

\section{ACKNOWLEDGEMENTS AND FUNDING}

This study was supported by National Natural Science Foundation of China (Grant No.81272837) and Shanghai municipal hospital emerging advanced technology joint research project (Grant No.SHDC12013122).

\section{CONFLICTS OF INTEREST}

The authors have declared that no competing 
interests exist.

\section{REFERENCES}

1. Chalfin HJ, Lee SB, Jeong BC, Freedland SJ, Alai H, Feng Z, Trock BJ, Partin AW, Humphreys E, Walsh PC and Han M. Obesity and long-term survival after radical prostatectomy. The Journal of urology. 2014; 192:11001104.

2. Mucksavage P, Mitchell C, Kutikov A, Wein AJ, Torigian D and Malkowicz SB. Anthropometric differences in obese men with biochemical failure after radical retropubic prostatectomy. Urologic oncology. 2012; 30:590-595.

3. Mistry T, Digby JE, Desai KM and Randeva HS. Obesity and prostate cancer: a role for adipokines. European urology. 2007; 52:46-53.

4. Neeland IJ, Ayers CR, Rohatgi AK, Turer AT, Berry JD, Das SR, Vega GL, Khera A, McGuire DK, Grundy SM and de Lemos JA. Associations of visceral and abdominal subcutaneous adipose tissue with markers of cardiac and metabolic risk in obese adults. Obesity. 2013; 21:E439-447.

5. Venkatasubramanian PN, Brendler CB, Plunkett BA, Crawford SE, Fitchev PS, Morgan G, Cornwell ML, McGuire MS, Wyrwicz AM and Doll JA. Periprostatic adipose tissue from obese prostate cancer patients promotes tumor and endothelial cell proliferation: a functional and MR imaging pilot study. The Prostate. 2014; 74:326-335.

6. Guenther M, James R, Marks J, Zhao S, Szabo A and Kidambi S. Adiposity distribution influences circulating adiponectin levels. Translational research : the journal of laboratory and clinical medicine. 2014; 164:270-277.

7. Allott EH, Masko EM and Freedland SJ. Obesity and prostate cancer: weighing the evidence. European urology. 2013; 63:800-809.

8. Tan W, Wang L, Ma Q, Qi M, Lu N, Zhang L and Han B. Adiponectin as a potential tumor suppressor inhibiting epithelial-to-mesenchymal transition but frequently silenced in prostate cancer by promoter methylation. The Prostate. 2015; 75:1197-1205.

9. Dhillon PK, Penney KL, Schumacher F, Rider JR, Sesso HD, Pollak M, Fiorentino M, Finn S, Loda M, Rifai N, Mucci LA, Giovannucci E, Stampfer MJ and Ma J. Common polymorphisms in the adiponectin and its receptor genes, adiponectin levels and the risk of prostate cancer. Cancer epidemiology, biomarkers \& prevention : a publication of the American Association for Cancer Research, cosponsored by the American Society of Preventive Oncology. 2011; 20:2618-2627.

10. Gu CY, Li QX, Zhu Y, Wang MY, Shi TY, Yang YY, Wang JC, Jin L, Wei QY and Ye DW. Genetic variations of the ADIPOQgene and risk of prostate cancer in Chinese Han men. Asian journal of andrology. 2014; 16:878-883.

11. Laumen H, Saningong AD, Heid IM, Hess J, Herder C, Claussnitzer M, Baumert J, Lamina C, Rathmann W,
Sedlmeier EM, Klopp N, Thorand B, Wichmann HE, Illig $\mathrm{T}$ and Hauner H. Functional characterization of promoter variants of the adiponectin gene complemented by epidemiological data. Diabetes. 2009; 58:984-991.

12. Qiao L, Maclean PS, Schaack J, Orlicky DJ, Darimont C, Pagliassotti M, Friedman JE and Shao J. C/EBPalpha regulates human adiponectin gene transcription through an intronic enhancer. Diabetes. 2005; 54:1744-1754.

13. Grabe N. AliBaba2: context specific identification of transcription factor binding sites. In silico biology. 2002; 2:S1-15.

14. Barth N, Langmann T, Scholmerich J, Schmitz G and Schaffler A. Identification of regulatory elements in the human adipose most abundant gene transcript-1 ( apM-1) promoter: role of SP1/SP3 and TNF-alpha as regulatory pathways. Diabetologia. 2002; 45:1425-1433.

15. Bub JD, Miyazaki $\mathrm{T}$ and Iwamoto $\mathrm{Y}$. Adiponectin as a growth inhibitor in prostate cancer cells. Biochemical and biophysical research communications. 2006; 340:11581166.

16. Lu JP, Hou ZF, Duivenvoorden WC, Whelan K, Honig A and Pinthus JH. Adiponectin inhibits oxidative stress in human prostate carcinoma cells. Prostate cancer and prostatic diseases. 2012; 15:28-35.

17. Gao $Q$ and Zheng J. Adiponectin-induced antitumor activity on prostatic cancers through inhibiting proliferation. Cell biochemistry and biophysics. 2014; 70:461-465.

18. Hebbard L and Ranscht B. Multifaceted roles of adiponectin in cancer. Best practice \& research Clinical endocrinology \& metabolism. 2014; 28:59-69.

19. Sengupta S, Peterson TR and Sabatini DM. Regulation of the mTOR complex 1 pathway by nutrients, growth factors, and stress. Molecular cell. 2010; 40:310-322.

20. Toren P and Venkateswaran V. Periprostatic adipose tissue and prostate cancer progression: new insights into the tumor microenvironment. Clinical genitourinary cancer. 2014; 12:21-26.

21. Ling H, Waterworth DM, Stirnadel HA, Pollin TI, Barter PJ, Kesaniemi YA, Mahley RW, McPherson R, Waeber G, Bersot TP, Cohen JC, Grundy SM, Mooser VE and Mitchell BD. Genome-wide linkage and association analyses to identify genes influencing adiponectin levels: the GEMS Study. Obesity. 2009; 17:737-744.

22. Kyriakou T, Collins LJ, Spencer-Jones NJ, Malcolm C, Wang X, Snieder H, Swaminathan R, Burling KA, Hart DJ, Spector TD and O'Dell SD. Adiponectin gene ADIPOQ SNP associations with serum adiponectin in two female populations and effects of SNPs on promoter activity. Journal of human genetics. 2008; 53:718-727.

23. Henneman P, Aulchenko YS, Frants RR, Zorkoltseva IV, Zillikens MC, Frolich M, Oostra BA, van Dijk KW and van Duijn CM. Genetic architecture of plasma adiponectin overlaps with the genetics of metabolic syndrome-related traits. Diabetes care. 2010; 33:908-913. 
24. Wassel CL, Pankow JS, Jacobs DR, Jr., Steffes MW, Li $\mathrm{N}$ and Schreiner PJ. Variants in the adiponectin gene and serum adiponectin: the Coronary Artery Development in Young Adults (CARDIA) Study. Obesity. 2010; 18:23332338 .

25. AlSaleh A, O'Dell SD, Frost GS, Griffin BA, Lovegrove JA, Jebb SA, Sanders TA and Group RS. Single nucleotide polymorphisms at the ADIPOQ gene locus interact with age and dietary intake of fat to determine serum adiponectin in subjects at risk of the metabolic syndrome. The American journal of clinical nutrition. 2011; 94:262-269.

26. Ong KL, Li M, Tso AW, Xu A, Cherny SS, Sham PC, Tse HF, Lam TH, Cheung BM, Lam KS and Investigators of the Hong Kong Cardiovascular Risk Factor Prevalence S. Association of genetic variants in the adiponectin gene with adiponectin level and hypertension in Hong Kong Chinese. European journal of endocrinology / European Federation of Endocrine Societies. 2010; 163:251-257.

27. Tong G, Wang N, Leng J, Tong X, Shen Y, Yang J, Ye $\mathrm{X}$, Zhou $\mathrm{L}$ and Zhou Y. Common variants in adiponectin gene are associated with coronary artery disease and angiographical severity of coronary atherosclerosis in type 2 diabetes. Cardiovascular diabetology. 2013; 12:67.

28. De Larochelliere E, Cote J, Gilbert G, Bibeau K, Ross MK, Dion-Roy V, Pibarot P, Despres JP and Larose E. Visceral/ epicardial adiposity in nonobese and apparently healthy young adults: association with the cardiometabolic profile. Atherosclerosis. 2014; 234:23-29.

29. Cnop M, Havel PJ, Utzschneider KM, Carr DB, Sinha MK, Boyko EJ, Retzlaff BM, Knopp RH, Brunzell JD and Kahn SE. Relationship of adiponectin to body fat distribution, insulin sensitivity and plasma lipoproteins: evidence for independent roles of age and sex. Diabetologia. 2003; 46:459-469.

30. Baglioni S, Cantini G, Poli G, Francalanci M, Squecco R, Di Franco A, Borgogni E, Frontera S, Nesi G, Liotta F, Lucchese M, Perigli G, Francini F, Forti G, Serio M and Luconi M. Functional differences in visceral and subcutaneous fat pads originate from differences in the adipose stem cell. PloS one. 2012; 7:e36569.

31. Wilt TJ, MacDonald R, Rutks I, Shamliyan TA, Taylor BC and Kane RL. Systematic review: comparative effectiveness and harms of treatments for clinically localized prostate cancer. Annals of internal medicine. 2008; 148:435-448.

32. Boorjian SA, Eastham JA, Graefen M, Guillonneau B, Karnes RJ, Moul JW, Schaeffer EM, Stief C and Zorn $\mathrm{KC}$. A critical analysis of the long-term impact of radical prostatectomy on cancer control and function outcomes. European urology. 2012; 61:664-675.

33. Huang SP, Levesque E, Guillemette C, Yu CC, Huang CY, Lin VC, Chung IC, Chen LC, Laverdiere I, Lacombe L, Fradet Y, Chang TY, Lee HZ, Juang SH and Bao BY. Genetic variants in microRNAs and microRNA target sites predict biochemical recurrence after radical prostatectomy in localized prostate cancer. International journal of cancer
Journal international du cancer. 2014; 135:2661-2667.

34. Huang SP, Lin VC, Lee YC, Yu CC, Huang CY, Chang TY, Lee HZ, Juang SH, Lu TL and Bao BY. Genetic variants in nuclear factor-kappa B binding sites are associated with clinical outcomes in prostate cancer patients. European journal of cancer. 2013; 49:3729-3737.

35. Chang CF, Pao JB, Yu CC, Huang CY, Huang SP, Yang YP, Huang CN, Chang TY, You BJ, Lee HZ, Hour TC and Bao BY. Common variants in IGF1 pathway genes and clinical outcomes after radical prostatectomy. Annals of surgical oncology. 2013; 20:2446-2452.

36. Cooperberg MR, Broering JM and Carroll PR. Risk assessment for prostate cancer metastasis and mortality at the time of diagnosis. Journal of the National Cancer Institute. 2009; 101:878-887.

37. Boorjian SA, Thompson RH, Tollefson MK, Rangel LJ, Bergstralh EJ, Blute ML and Karnes RJ. Long-term risk of clinical progression after biochemical recurrence following radical prostatectomy: the impact of time from surgery to recurrence. European urology. 2011; 59:893-899.

38. Mottet N, Bellmunt J, Bolla M, Joniau S, Mason M, Matveev V, Schmid HP, Van der Kwast T, Wiegel T, Zattoni $\mathrm{F}$ and Heidenreich A. EAU guidelines on prostate cancer. Part II: Treatment of advanced, relapsing, and castration-resistant prostate cancer. European urology. 2011; 59:572-583.

39. Chen C, Lu FC and Department of Disease Control Ministry of Health PRC. The guidelines for prevention and control of overweight and obesity in Chinese adults. Biomedical and environmental sciences : BES. 2004; 17 Suppl:1-36.

40. Zhu Y, Wang HK, Zhang HL, Yao XD, Zhang SL, Dai B, Shen YJ, Liu XH, Zhou LP and Ye DW. Visceral obesity and risk of high grade disease in clinical tla renal cell carcinoma. The Journal of urology. 2013; 189:447-453.

41. van Roermund JG, Hinnen KA, Tolman CJ, Bol GH, Witjes JA, Bosch JL, Kiemeney LA and van Vulpen M. Periprostatic fat correlates with tumour aggressiveness in prostate cancer patients. BJU international. 2011; 107:17751779. 